\title{
Intravascular lung coagulopathy by COVID-19
}

\author{
Laura Montero Martín*, Begoña Fernández-Jiménez \\ Haematology and Haemotherapy Department, Mostoles University Hospital, Madrid, Spain
}

\section{Introduction}

Coronavirus disease 2019 (COVID-19), caused by a new coronavirus (SARS-CoV-2, severe acute respiratory syndrome coronavirus 2), is a highly contagious disease that first appeared in Wuhan, China, in December 2019 [1]. On 30 January 2020, the World Health Organisation (WHO) declared that the COVID-19 outbreak constituted a public health emergency of international concern (PHEIC) [2, 3]. On 11 March 2020, the WHO officially declared a pandemic [3].

Most infected patients have mild symptoms including fever, fatigue, and cough [1, 4]. However, severe cases can progress rapidly and develop adult respiratory distress syndrome (ARDS) with coagulopathy [1, 4]. The latter is already described as one of the most important independent poor prognostic factors $[5,6]$. Thus, the objective of this investigation was to analyse the coagulation alterations produced by COVID-19, and assess whether they present different characteristics to the coagulopathy present in other pathologies.

\section{Methods}

From the Haemostasis and Coagulation Laboratory, we selected 15 consecutive patients who had D-dimer values at least four times higher than normal $(0.1-0.5 \mu \mathrm{g} / \mathrm{mL})$, positivity by polymerase chain reaction (PCR) of SARS-CoV-2, and pneumonia on chest radiography. All of them were admitted during March 2020 to the Mostoles University Hospital (Madrid), which cares for a population of approximately 169,000 patients. During the months of March and April, the number of new patients with COVID-19 pneumonia admitted to the Hospital was 515 and 358, respectively.

All patients, coinciding with a scheduled extraction, had a blood sample drawn to determine basic coagulation parameters such as the prothrombin time ratio (PT ratio), activated partial thromboplastin time ratio (APTT ratio), thrombin (TT), D-dimer and fibrinogen. In addition, the von Willebrand factor (vVF:Ag and vWF:Rco), blood group ABO, natural anticoagulants such as antithrombin (AT), protein $C$ and protein $S$, were analysed, and coagulation factors II, V, VII, VIII, IX, X, XI, and XII were dosed. All of the determinations were made using STA Compact MAX and R MAX analysers, along with their original reagents (Diagnostica Stago, Saint-Denis, France). A clot solubility assay in 5M urea was performed as a factor XIII deficiency screening method. The determination of lactate dehydrogenase, C-reactive protein (Cobas Roche with its original reagents) and ferritin (ECLIA electrochemiluminescence) were also included in the analysis.

In addition, we collected demographic data of the patients (age and sex), the number of hospital admission days at the time of sample extraction, the occurrence of thrombotic events such as pulmonary thrombosis diagnosed by imaging test [angiography computed tomography (angio$\mathrm{CT}$ )], and data showing if they were previously receiving antithrombotic prophylaxis. Moreover, the severity of the patients' infectious picture, the appearance of other related complications, and information determining if eventually the patient improved or died, were also acquired.

\section{Results}

Out of the 15 patients included in the study, seven were women and eight were men, with a median age of 63 years (range 30-86). Median days of hospitalisation at the time of sample collection was 6 (range 1-12) (Table I). All patients presented pneumonia confirmed by chest radiography from admission; 11 of them required invasive mechanical ventilation in the Intensive Care Unit. Before admission, none of them were on anticoagulant treatment. Prophylactic low-molecular-weight heparin (LMWH) was prescribed at standard doses (40 $\mathrm{mg}$ of enoxaparin per day) from the moment of admission, except for two patients who empirically received anticoagulant doses because they presented D-dimer levels 20 times higher than normal (0.1-0.5 $\mathrm{\mu g} / \mathrm{mL})$; and one who did not receive it due to thrombocytopenia $\left(22 \times 10^{3} / \mu \mathrm{L}\right.$ platelets $)$.
*Address for correspondence: Laura Montero Martín,

Mostoles University Hospital, c/Luis Montes s/n Móstoles,

Madrid 28935, Spain, e-mail: Laura.mtrm@gmail.com
PTHiT Copyright $\odot 2021$

The Polish Society of Haematologists and Transfusiologists,

Insitute of Haematology and Transfusion Medicine.

All rights reserved. 
Table I. Clinical characteristics of patients

\begin{tabular}{|c|c|}
\hline Parameter & Value \\
\hline Age & Median 63 years (range $30-86$ ) \\
\hline Sex & $\begin{array}{l}7(46.7 \%) \text { female } \\
8(53.3 \%) \text { male }\end{array}$ \\
\hline $\begin{array}{l}\text { Thrombotic complica- } \\
\text { tions diagnosed } \\
\text { by imaging test }\end{array}$ & $\begin{array}{l}6(60 \%) \text { pulmonary thrombosis } \\
1(6.7 \%) \text { ischaemic stroke } \\
1(6.7 \%) \text { myocardial infarction }\end{array}$ \\
\hline $\begin{array}{l}\text { Haemorrhagic } \\
\text { complications }\end{array}$ & $0(0 \%)$ \\
\hline Clinical evolution & $\begin{array}{l}7(46.7 \%) \text { death } \\
5(33.3 \%) \text { hospital discharge } \\
3(20 \%) \text { ICU }\end{array}$ \\
\hline
\end{tabular}

ICU - Intensive Care Unit

10 of the 15 patients underwent angio-CT after observing the elevation of D-dimer, and six of the 10 (60\%) had peripheral pulmonary thrombosis. As previously discussed, $5 / 6$ patients were receiving prophylactic LMWH at standard doses prior to diagnosis. The remaining patient did not receive it, because at the time of admission he had thrombocytopenia of $22 \times 10^{3} / \mu \mathrm{L}$, presenting a thrombotic event 48 hours after it. This patient, who was diagnosed with essential thrombocythemia, presented a multiple ischaemic stroke with subsequent haemorrhagic transformation, as well as an acute myocardial infarction.

Subsequently, eight patients died as a result of COVID-19 lung infection, five were definitively discharged, and two remain in long-stay hospitals for recovery at the time of writing this review (Table I).

D-dimer values at the time of the study were between 2.39 and $172.33 \mu \mathrm{g} / \mathrm{mL}$ (median $16.39 \mu \mathrm{g} / \mathrm{mL}$ ); significantly higher in relation to the DD value on admission day (median $0.86 \mu \mathrm{g} / \mathrm{mL}$, range $0.47-13.19 \mu \mathrm{g} / \mathrm{mL}$ ). The platelet count was within normality in $80 \%$ of the patients and slightly decreased in the rest $\left(>80 \times 10^{3} / \mu \mathrm{L}\right)$. The PT ratio was also normal, except for one patient in whom the determination after the admission figure was normalised. Fibrinogen was above the upper limit of normality in $85.7 \%$ of patients $(12 / 14)$, while in the rest it was normal, and the APTT ratio was normal or shortened. The TT was normal, except in three patients due to the effect of LMWH (Table II).

None of the patients included in the study met DIC criteria. No significant decrease in AT, PC and PS was observed. Only one patient had a slightly decreased determination of AT (76\%) and PC (64\%), and another of coagulative PS (51\%). In both patients, the determination was made in the context of a pulmonary thrombosis diagnosed by angio-CT, so the decrease was not measurable given the consumption of coagulation factors in the acute thrombotic event.
A highly increased factor VIII and VWF (medians of $267 \%$ and $466.5 \%$ respectively) were found in all patients. The blood group was tested in 14 patients, with nine of them being from blood group $A$, four from group 0 , and one from group $B$. No significantly higher values of factor VIII or vWF were observed in the non-0 groups compared to the 0 group.

We did not observe a significant decrease in the rest of the coagulation factors, with the exception of four patients who presented a minimal decrease in factors II and V, and one patient in factor XII (Table II).

\section{Discussion}

The main finding of our study was that there is no factor consumption, nor a decrease in natural anticoagulants, while all the patients presented a factor VIII and a VWF greatly increased, reflecting the state of hypercoagulability they presented, although this assertion is just a hypothesis that requires further investigation.

These findings are in contrast to findings reported in other studies about coagulopathy in infectious diseases. As observed in our study, the alterations found in patients with severe SARS-CoV-2 infection are different from the coagulopathy found in disseminated intravascular coagulation (DIC) [7]. This finding is reflected in the constant observation that platelet counts and fibrinogen concentrations do not decrease significantly in patients with COVID-19, despite the marked increase in D-dimer concentrations [8, 9].

However, given the sparse knowledge that we still have about the SARS-CoV-2 infection, we believe that the analytical alterations do not offer a good reflection of the alterations at the local level. Whether microthrombosis exists at this level is beyond the scope of this study.

We do not have a real incidence of thrombotic events. In our study, six patients were diagnosed with pulmonary thrombosis after requesting imaging tests. Some of the remaining patients may also have it, but it is an event that has not been confirmed. At the present time, a retrospective study is underway, organized by Dr. Llamas Sillero, Head of Haematology Department of Fundacion Jimenez Diaz University Hospital (Madrid), and endorsed by the Madrid Society of Haematology, which aims to make an accurate estimation of them in the Community of Madrid.

Thus, the concept of pulmonary intravascular coagulopathy (CIP) seems correct to us [9] for this condition with activation of coagulation located in the lung, where an environment of hypercoagulability occurs, not caused directly by the virus, but rather secondary to three triggers:

1) inflammation, both produced by cellular damage caused by cells damaged by the virus (type II pneumocytes), as well as secondary to innate immunity. This inflammation would activate coagulation through tissue factor expressed by macrophages, neutrophils, 
Table II. Laboratory parameters

\begin{tabular}{|c|c|c|c|c|c|}
\hline Parameter & Reference range & $\mathrm{n}$ & Median (min-max) & $\begin{array}{l}<\text { lower limit } \\
\text { Reference }\end{array}$ & $\begin{array}{c}\text { > upper limit } \\
\text { Reference }\end{array}$ \\
\hline LDH & $135-225 \mathrm{U} / \mathrm{L}$ & 15 & $479(227-768)$ & $0(0 \%)$ & $15(100 \%)$ \\
\hline Ferritin & $50-220 \mathrm{ng} / \mathrm{mL}$ & 15 & $1,544(394-6,230)$ & $0(0 \%)$ & $15(100 \%)$ \\
\hline CRP & $0-5 \mathrm{mg} / \mathrm{L}$ & 15 & $239.4(0.7-598.8)$ & $0(0 \%)$ & 14 (93.3\%) \\
\hline Platelets & $150-450 \times 10^{3} / \mu \mathrm{L}$ & 15 & $294(81-426)$ & $3(20 \%)$ & $0(0 \%)$ \\
\hline PT ratio & $0.9-1.25$ & 15 & $1.12(1-1.31)$ & $0(0 \%)$ & $1(6.7 \%)$ \\
\hline APTT ratio & $0.86-1.18$ & 15 & $0.93(0.8-1.04)$ & $2(13.3 \%)$ & $0(0 \%)$ \\
\hline Fibrinogen & $200-400 \mathrm{mg} / \mathrm{dL}$ & 14 & $535.5(201-848)$ & $0(0 \%)$ & $12(85.7 \%)$ \\
\hline D-dimer on admission & $0.1-0.5 \mu \mathrm{g} / \mathrm{mL}$ & 13 & $0.86(0.47-13.2)$ & $0(0 \%)$ & $11(84.6 \%)$ \\
\hline D-dimer at time of study & & 15 & $16.39(2.39-172.3)$ & $0(0 \%)$ & $15(100 \%)$ \\
\hline TT & $16-21 s$ & 12 & 18.75 (16.4-27.1) & $0(0 \%)$ & $3(25 \%)$ \\
\hline Factor II & $70-120 \%(95 \%)$ & 15 & $104(66-129)$ & $2(13.3 \%)$ & $1(6.7 \%)$ \\
\hline Factor V & $70-120 \%(95 \%)$ & 15 & $113(52-122)$ & $2(13.3 \%)$ & $5(33.3 \%)$ \\
\hline Factor VII & $55-170 \%$ (112.5\%) & 15 & $99(55-183)$ & $0(0 \%)$ & $3(20 \%)$ \\
\hline Factor X & $70-120 \%(95 \%)$ & 15 & $106(77-135)$ & $0(0 \%)$ & $4(26.7 \%)$ \\
\hline Factor VIII & $60-150 \%$ (105\%) & 15 & $267(128-383)$ & $0(0 \%)$ & $15(100 \%)$ \\
\hline vWF:Ag & $50-150 \%$ (100\%) & 12 & $406.5(255-420)$ & $0(0 \%)$ & $12(100 \%)$ \\
\hline vWF:Rco & $50-200 \%$ (125\%) & 10 & 236 (from 156 to >200) & $0(0 \%)$ & $7(46.7 \%)$ \\
\hline Factor IX & $60-150 \%(105 \%)$ & 15 & $151(107-225)$ & $0(0 \%)$ & $8(53.3 \%)$ \\
\hline Factor XII & 60-150\% (105\%) & 15 & $101(35-139)$ & $1(6.7 \%)$ & $0(0 \%)$ \\
\hline Factor XIII* & & 15 & \multicolumn{3}{|c|}{ Negative 15 (100\%) } \\
\hline AT III & $80-120 \%$ (100\%) & 15 & $115(76-135)$ & $1(6.7 \%)$ & $5(33.3 \%)$ \\
\hline PC & $70-130 \%$ (100\%) & 15 & 99 (64-181) & $1(6.7 \%)$ & $3(20 \%)$ \\
\hline \multirow[t]{2}{*}{ Free PS } & M: 70-148\% (109\%) & 8 & $109.5(87-179)$ & $0(0 \%)$ & $1(12.5)$ \\
\hline & F: 50-134 (92\%) & 7 & $90(67-129)$ & $0(0 \%)$ & $0(0 \%)$ \\
\hline \multirow[t]{2}{*}{ Functional PS } & M: 77-143\% (110\%) & 8 & $94.5(89-137)$ & $0(0 \%)$ & $0(0 \%)$ \\
\hline & F: 55-123 (89\%) & 7 & $64(51-125)$ & $1(14.3 \%)$ & $1(14.3 \%)$ \\
\hline $\mathrm{APC}$ ratio & $\geq 2.9$ & 13 & $3.58(3.27-4.34)$ & $0(0 \%)$ & \\
\hline
\end{tabular}

*Clot solubility assay in urea 5M; LDH - lactate dehydrogenase; CRP - C-reactive protein; PT - prothrombin time; APTT - activated partial thromboplastin time; TT - thrombin time; vWF - von Willebrand factor; $\mathrm{Ag}$ - antigen; Rco - ristocetin cofactor; AT - antithrombin; PC - protein C; PS - protein S; f; APC - activated protein C ratio

endothelium, platelets and extracellular vesicles, phosphatidyl serine, free DNA, damage-associated molecular patterns (DAMPs), extracellular neutrophil traps (NETs) or platelet activation;

2) the endothelial lesion, which loses its protective layer and alters its regulatory function of fibrinolysis in order to avoid the formation of thrombi on its surface, and its regulatory function of vascular permeability. In addition, there is direct endothelial damage from the virus since the endothelium, like type II pneumocytes, also has angiotensin-converting enzyme (ACE2R) receptors [10];

3) hypoxia that causes cellular damage and regulates coagulation and fibrinolysis through hypoxia-inducible transcription factors (HIFs) [11].

The role of immunothrombosis in containing bacteria is well known, but its role in viral infections is not well understood [9]. In any case, when it occurs excessively, as is happening in many of the patients with SARS-CoV-2 pneumonia, it can be more harmful than the virus itself.

\section{Conclusions}

After analysing the results of the referred determinations, we can establish:

- classical DIC does not occur in COVID-19 associated coagulopathy $(\mathrm{CAC})$. There is no consumption of factors, nor a decrease in natural anticoagulants. There is a significant increase in factor VIII and VWF, due to extensive endothelial injury, which seems to play a leading role in pulmonary microthrombosis, and in injury to other affected organs (heart, kidneys, small intestine); 
- the elevation of D-dimer suggests that there is local coagulation activation in the lung, where fibrinolysis is increased, but with an overall balance in favour of thrombosis;

- what analytics 'globally' reflects does not seem to represent what is happening at the local level. In the places where microthrombosis is taking place, it is very likely that the levels of factors and anticoagulants are different from those found in this study, which points to the idea of a different haemostatic microenvironment. Regarding the anticoagulation in these patients, given the extensive endothelial injury, we suggest that heparin, which apart from being an anticoagulant can also protect the endothelium [8] which is especially affected in this pathology, would be, given the data available so far, the chosen anticoagulant drug for both thromboprophylaxis and for the treatment of established venous thromboembolism (VTE) [8, 12], at least in the acute moment. It will be interesting to observe the outcomes of patients who, for various reasons, have been treated with direct anticoagulants.

\section{Acknowledgments}

We thank all patients involved in the study and the haematology laboratory technicians.

\section{Authors' contributions}

BFJ - study design; LMM, BFJ - selecting patients, analysing variables, writing article.

\section{Conflict of interest \\ None.}

\section{Financial support}

None.

\section{Ethics}

The work described in this article has been carried out in accordance with The Code of Ethics of the World Medical Association (Declaration of Helsinki) for experiments involving humans; EU Directive 2010/63/ EU for animal experiments; Uniform requirements for manuscripts submitted to biomedical journals.

\section{References}

1. Hunt B, Retter A, McClintock C. Practical guidance for the prevention of thrombosis and management of coagulopathy and disseminated intravascular coagulation of patients infected with COVID-19. https:// //thrombosisuk.org/covid-19-thrombosis.php (April 9, 2020).

2. Guan WJ, Ni Zy, Hu Yu, et al. Clinical characteristics of coronavirus disease 2019 in China. N Engl J Med. 2020; 382(18): 1708-1720, doi: 10.1056/nejmoa2002032, indexed in Pubmed: 32109013.

3. World Health Organization. WHO Director-General's opening remarks at the media briefing on COVID-19. https://www.who.int/director-general/speeches/detail/who-director-general-s-openingremarks-at-the-media-briefing-on-covid-19---11-march-2020 (March 11, 2020).

4. Huang C, Wang Y, Li X, et al. Clinical features of patients infected with 2019 novel coronavirus in Wuhan, China. Lancet. 2020; 395(10223): 497-506, doi: 10.1016/S0140-6736(20)30183-5, indexed in Pubmed: 31986264.

5. Tang N, Li D, Wang X, et al. Abnormal coagulation parameters are associated with poor prognosis in patients with novel coronavirus pneumonia. J Thromb Haemost. 2020; 18(4): 844-847, doi: 10.1111/ /jth.14768, indexed in Pubmed: 32073213.

6. Lillicrap D. Disseminated intravascular coagulation in patients with 2019-nCoV pneumonia. J Thromb Haemost. 2020; 18(4): 786-787, doi: 10.1111/jth.14781, indexed in Pubmed: 32212240.

7. Levi M, van der Poll T. Coagulation and sepsis. Thromb Res. 2017; 149: 38-44, doi: 10.1016/j.thromres.2016.11.007, indexed in Pubmed: 27886531.

8. Tang N, Bai $\mathrm{H}$, Chen X, et al. Anticoagulant treatment is associated with decreased mortality in severe coronavirus disease 2019 patients with coagulopathy. J Thromb Haemost. 2020; 18(5): 1094-1099, doi: 10.1111/jth.14817, indexed in Pubmed: 32220112.

9. McGonagle D, O'Donnell J, Sharif K, et al. Immune mechanisms of pulmonary intravascular coagulopathy in COVID-19 pneumonia. Lancet Rheumatol. 2020; 2(7): e437-e445, doi: 10.1016/s26659913(20)30121-1.

10. Li H, Liu L, Zhang D, et al. SARS-CoV-2 and viral sepsis: observations and hypotheses. The Lancet. 2020; 395(10235): 1517-1520, doi: 10.1016/s0140-6736(20)30920-x.

11. Yan SF, Mackman N, Kisiel W, et al. Hypoxia/Hypoxemia-Induced activation of the procoagulant pathways and the pathogenesis of ischemia-associated thrombosis. Arterioscler Thromb Vasc Biol. 1999; 19(9): 2029-2035, doi: 10.1161/01.atv.19.9.2029, indexed in Pubmed: 10479642.

12. Thachil J. The versatile heparin in COVID-19. J Thromb Haemost. 2020; 18(5): 1020-1022, doi: 10.1111/jth.14821, indexed in Pubmed: 32239799. 